http://jmscr.igmpublication.org/home/

ISSN (e)-2347-176x ISSN (p) 2455-0450

crossref DOI: https://dx.doi.org/10.18535/jmscr/v7i8.112

Journal Of Medical Science And Clinical Research

IGM Publication

An Official Publication of IGM Publication

\title{
A Randomised Controlled Trial of 12 Hours vs 24 Hours Betamethasone Dosing Interval in Preterm Premature Rupture of Membranes for Prevention of Respiratory Distress Syndrome (RDS) in Neonates
}

\author{
Authors
}

\section{Dr Pratibha Gupta ${ }^{1}$, Dr Sandeep Sharma ${ }^{2 *}$, Dr Vinay Kumar ${ }^{3}$}

${ }^{1}$ Senior Resident, Department of OBG Dr YS Parmar Govt. Medical College, Nahan HP.

${ }^{2}$ Senior Resident, Department of OBG, Indira Gandhi Medical College, Shimla, HP

${ }^{3}$ Junior Resident Department of Paediatrics, Indira Gandhi Medical College, Shimla, HP

*Corresponding Author

Dr Sandeep Sharma

Senior Resident, Department of OBG, Indira Gandhi Medical College, Shimla, HP, India

\begin{abstract}
Preterm premature rupture of membranes is an important cause of preterm delivery. Management includes antibiotic therapy and a course of steroids. Current approach is to give two doses of steroid betamethasone 24 hours apart. We recruited 100 women with pPROM between 26-34 weeks period of gestation, divided into two groups of 50 each, receiving betamethasone two doses either 12 hours or 24 hours apart. Aim was to see difference in outcome of Respiratory distress syndrome (RDS) and other morbidities like intraventricular heamorrhage (IVH), necrotizing enterocolitis (NEC) and Neonatal sepsis. We found no statistical difference in the outcome of RDS and other morbidities except birth asphyxia. We concluded that women with Pprom can be offered course of steroids with 12 hour interval. Moreover it had the advantage of having more women completing the course of steroids before delivery.
\end{abstract}

Keywords: Preterm premature rupture of membranes (pPROM), respiratory distress syndrome (RDS), steroid, betamethasone.

\section{Introduction}

Preterm premature rupture of membranes (pPROM) is an important cause of premature delivery. Although exact etiology of pPROM is unknown but various risk factors associated are: Black race, ${ }^{1}$ low socioeconomic status, smoking, history of sexually transmitted infections, preterm delivery and uterine distension (e.g., polyhydramnios, multifetal pregnancy). ${ }^{2}$

pPROM is strongly associated with maternal infectious morbidity like chorioamnionitis, endometritis and bacteremia. Management of women with pPROM requires an assessment of benefits and risks of continuing pregnancy vs immediate delivery. It complicates only $2 \%$ pregnancies but is associated with $40 \%$ of preterm deliveries. ${ }^{3}$ When membranes rupture between 28 34 weeks, 50\%women go into labour within 24 hours and $80-90 \%$ within one week. ${ }^{4}$ The currently accepted approach is based on expectant management between 24 to 32 weeks of gestation in combination with adjunctive antibiotic therapy and a course of steroids. 
The most common cause of deaths among preterm birth is respiratory distress syndrome (RDS), others being necrotising enterocolitis (NEC), intraventricular haemorrhage (IVH), chronic lung disease (CLD), neonatal sepsis.

Research has shown that glucocorticoid administration has a significant beneficial effect for preterm births as it decreases the incidence of respiratory distress syndrome in infants delivered between $26 \& 34$ weeks of gestation, also reduces the incidence of intraventricular haemorrhage, improves circulatory stability, reduces the need for oxygen \& ventilator support and reduces overall neonatal mortality. Currently the National Institute Of Health recommended 2 doses of $12 \mathrm{mg}$ of betamethasone (BTM) intramuscular 24 hours apart while total doses was based on efficacy found on animal studies. The NIH admits 2 doses regimen was chosen arbitrarily and has recognised as an urgent need for studies on dosing interval variations. $^{2,5}$

$25-40 \%$ of women at risk for preterm delivery deliver within 24 hours prior to receiving complete course of steroids. Only 5\% of these deliver within 12 hours. ${ }^{6}$ If 24 hours dosing schedule is followed several women may miss to receive the second dose and will go into preterm labour and deprived of its benefits.

So the present study is undertaken to compare the efficacy of the two dosing schedules in reducing the incidence of respiratory distress syndrome in preterm neonate born to mother with pPROM.

\section{Aims and Objectives}

To determine whether there is difference in the incidence of RDS (Respiratory distress syndrome) in neonates when administrating 2 doses of betamethasone $12 \mathrm{mg}$ intramuscular 12 hours vs. 24 hours apart in preterm premature rupture of membranes.

\section{Methodology}

This randomised study was conducted in Clean Labour Room \& Antenatal OPD of Department of Obstetrics and Gynaecology of Postgraduate
Institute of Medical Education and Research, Chandigarh. A total of 100 women with preterm premature rupture of membranes (pPROM) between 26 to 34 weeks period of gestation were recruited for this study after assessing their eligibility criteria. Pregnant women with period of gestation less than 26 weeks or more than 34 weeks, women having received steroids other than betamethasone, congenital malformation in fetus, intrauterine fetal death and women having features of chorioamnionitis were excluded from the study.

After inclusion criteria were fulfilled, written informed consent was taken from all women prior to recruitment for this study. Detailed history was recorded on pre designed performa which was followed by general physical and obstetric examination. Obstetric sonography was done to assess fetal biometry, amniotic fluid along with fetal biophysical profile. Non stress test was also performed for complete assessment of fetal wellbeing. Screening for major congenital anomalies was done in case it had not been done during routine sonography between 16 to 20 weeks. A speculum examination was performed under all aseptic conditions and swabs were taken from cervix for bacterial culture and sensitivity testing. Haematological tests including haemoglobin, TLC, DLC, and urine analysis (routine and culture) were done at admission. Intravenous Ampicillin 2 gm every $6 \mathrm{hrs}$ for 48 hours followed by oral amoxicillin $500 \mathrm{mg}$ every 8 hours for 5 days and oral Erythromycin 250mg were given every 6 hourly for 7 days starting from the time of admission. After the diagnosis of pPROM was confirmed based on history, clinical examination or on ultrasonography then according to randomisation patient was given injection betamethasone in two doses either 12 hours apart or 24 hours apart. If patient was on conservative management and shifted toward details of cervical swabs sent for culture were noted and monitoring was done till the women went into labour either spontaneously or after induction. Patients were monitored daily for the signs and symptoms of 
chorioamnionitis. Various parameters like the decision for termination of expectant management, the mode of delivery and neonatal outcomes with regard to development of Respiratory Distress Syndrome (RDS), Intraventricular heamorrhage (IVH), Necrotising Enterocolitis (NEC) and Neonatal Sepsis were noted.

\section{Statistical Analysis}

Quantitative data was presented as mean \pm SD or median and inter quartile range, as appropriate. Normality of data was be checked by measures of Kolmogorov Smirnov tests of normality. For normally distributed data means were be compared using unpaired t-test. For skewed data or ordinal data Mann-Whitney test was be applied. For categorical variables; number \& percentages were be calculated .Chi-sq test or Fisher's exact test was applied for comparison of categorical data.. All calculations were two sided \& were performed using SPSS version 15 (Statistical Packages for the Social Sciences, Chicago, IL). A $P$ value of $<0.05$ was considered to indicate statistical significance.

\section{Approval by the Research and Ethics Committee}

The protocol was approved by institute's Ethical Committee and guidelines set up by ICMR (1994), and Helsinki Declaration (modified 2000) was adhered in all patients enrolled in the study.

\section{Results}

Table 1 shows the distribution of women according to the period of gestation at the time of pPROM. The mean gestational age was $31^{3 / 7}$ weeks in group A and $30^{2 / 7}$ weeks in group B at the time of pPROM. The women in the group A had higher mean gestational age at the time of pPROM than in group $B(p=0.067)$ but the difference was not clinically significant, hence the women in two groups were matched according to period of gestation at time of Pprom.
Table 1: Period of gestation at the time of pPROM

\begin{tabular}{|c|c|c|c|}
\hline $\begin{array}{l}\text { Gestational age } \\
\text { (weeks) }\end{array}$ & $\begin{array}{c}\text { Group A } \\
\left(\mathbf{n}_{\mathbf{1}}=\mathbf{5 0}\right)\end{array}$ & $\begin{array}{l}\text { Group B } \\
\left(\mathbf{n}_{\mathbf{2}}=\mathbf{5 0}\right)\end{array}$ & $\mathrm{p}$ value \\
\hline $23-26^{6 / 7}$ & 1 & 7 & \\
\hline $27-30^{6 / 7}$ & 22 & 19 & \\
\hline $31-33^{6 / 7}$ & 27 & 24 & \\
\hline Mean & $31^{3 / 7}$ weeks & $30^{2 / 7}$ weeks & 0.067 \\
\hline
\end{tabular}

Table 2 shows the number of doses either single or both received by the women in the two groups. In total 15 patients out of 100 went into spontaneous labour and delivered before receiving the second dose. These women were more in group B. However the difference was not found to be significant.

Table 2: Dose of Betamethasone received in both groups

\begin{tabular}{|l|c|c|}
\hline Doses Received & $\begin{array}{c}\text { Group A } \\
(\mathbf{n = 5 0 )}\end{array}$ & $\begin{array}{c}\text { Group B } \\
(\mathbf{n = 5 0})\end{array}$ \\
\hline 1 & $5(10 \%)$ & $10(20 \%)$ \\
\hline 2 & $45(90 \%)$ & $40(80 \%)$ \\
\hline$p$ value & \multicolumn{2}{|c|}{0.161} \\
\hline
\end{tabular}

Table 3 shows the mode of delivery in the two groups. More patients in the group B delivered vaginally but the difference however was not found to be statistically significant. Of the women in the group A, 36(73.5\%) out of 49 had vaginal delivery. One woman delivered outside PGIMER. Two $(4.1 \%)$ out of 36 needed forceps delivery in view of fetal bradycardia. Thirteen underwent caesarean section. Emergency caesarean was done in $12(24.5 \%)$ out of 13 and $1(2.2 \%)$ patient had undergone elective caesarean. In the group B, $41(82 \%)$ out of 50 had vaginal delivery and $9(18 \%)$ out of 50 had undergone emergency caesarean section. One patient of the 41 in group B who had a vaginal delivery had a forceps delivery.

Table 3: Mode of delivery in both groups

\begin{tabular}{|l|c|c|c|}
\hline Mode of delivery & $\begin{array}{c}\text { Group A } \\
(\mathbf{n = 4 9})\end{array}$ & $\begin{array}{c}\text { Group B } \\
(\mathbf{n = 5 0 )}\end{array}$ & \\
\hline Vaginal & $34(69.4 \%)$ & $40(80 \%)$ & \multirow{2}{*}{0.513} \\
\cline { 1 - 3 } Emergency LSCS & $12(24.5 \%)$ & $9(18 \%)$ & \multirow{2}{*}{0} \\
\cline { 1 - 3 } Elective LSCS & $1(2.2 \%)$ & 0 & \\
\cline { 1 - 3 } Instrumentation & $2(4.1 \%)$ & $1(2 \%)$ & \\
\cline { 1 - 3 }
\end{tabular}


Table 4,5 show the relation between post partum fever with various markers of infection. Post partum fever was recorded in 4 out of 100 patients, 3 patients in group A and 1 in group B. 3 out of these 4 had chorioamnionitis. In group A 7 patients developed chorioamnionitis, 3 had positive cervical swab and 2 had positive placental membrane culture. While in group B 7 had positive cervical swab and 5 had positive placental membrane culture.

Table 4: Relation of post-partum fever with various markers of infection

\begin{tabular}{|l|c|c|c|}
\hline Marker of infection & $\begin{array}{c}\text { Post-partum } \\
\text { fever } \\
(\mathrm{n}=4)\end{array}$ & $\begin{array}{c}\text { No post- } \\
\text { partum fever } \\
(\mathrm{n}=96)\end{array}$ & $\mathrm{p}$ value \\
\hline $\begin{array}{l}\text { Clinical } \\
\text { chorioamnionitis }\end{array}$ & $3(75 \%)$ & $10(10.4 \%)$ & 0.01 \\
\hline $\begin{array}{l}\text { Cervical swab } \\
\text { positivity }\end{array}$ & $2(50 \%)$ & $15(15.6 \%)$ & 0.26 \\
\hline $\begin{array}{l}\text { Placental membrane } \\
\text { culture positive }\end{array}$ & $1(25 \%)$ & $6(6.2 \%)$ & 0.51 \\
\hline
\end{tabular}

Table 5: Relation of various markers of infection in both groups

\begin{tabular}{|l|c|c|c|}
\hline Marker of infection & $\begin{array}{c}\text { Group A } \\
\left(\mathbf{n}_{\mathbf{1}}=\mathbf{4 9}\right)\end{array}$ & $\begin{array}{c}\text { Group B } \\
\left(\mathbf{n}_{\mathbf{2}}=\mathbf{5 0}\right)\end{array}$ & p value \\
\hline Postpartum fever & $3(6.12 \%)$ & $1(2 \%)$ & 0.617 \\
\hline $\begin{array}{l}\text { Clinical } \\
\text { chorioamnionitis }\end{array}$ & $7(14.28 \%)$ & $6(12 \%)$ & 0.766 \\
\hline $\begin{array}{l}\text { Cervical swab } \\
\text { positivity }\end{array}$ & $3(6.12 \%)$ & $7(14.3 \%)$ & 0.182 \\
\hline $\begin{array}{l}\text { Placental membrane } \\
\text { culture positive }\end{array}$ & $2(4.08 \%)$ & $5(25 \%)$ & 0.214 \\
\hline
\end{tabular}

The overall mean birth weights in the group A was $1735.60 \pm 392.67$ grams, and in the group B was $1588.34 \pm 409.34$ grams. The difference in the two groups was not statistically significant.

Table 6 shows the incidence of neonatal complications in the two groups. Birth asphyxia was more in group B which was found to be clicnically significant. In others respiratory distress syndrome was more in group B. Rest of the complications including Neonatal Jaundice, Neonatal Sepsis and Intraventricular Heammorhage were more in group A but the difference was not found to be clinically significant.
Table 6: Neonatal complications in the two groups

\begin{tabular}{|l|c|c|c|}
\hline Complication & $\begin{array}{c}\text { Group A } \\
\left(\mathbf{n}_{\mathbf{1}}=\mathbf{4 9}\right)\end{array}$ & $\begin{array}{c}\text { Group B } \\
\left(\mathbf{n}_{\mathbf{2}}=\mathbf{5 0}\right)\end{array}$ & $\begin{array}{c}\mathbf{p} \\
\text { value }\end{array}$ \\
\hline Birth asphyxia & 0 & $6(12 \%)$ & 0.03 \\
\hline $\begin{array}{l}\text { Respiratory } \\
\text { distress syndrome }\end{array}$ & $6(12.2 \%)$ & $11(22 \%)$ & 0.183 \\
\hline Neonatal jaundice & $49(100 \%)$ & $47(94 \%)$ & 0.927 \\
\hline Neonatal Sepsis & $\begin{array}{c}25 \\
(51.02 \%)\end{array}$ & $24(48 \%)$ & 0.841 \\
\hline $\begin{array}{l}\text { Intraventricular } \\
\text { haemorrhage }\end{array}$ & $3(6.12 \%)$ & $1(2 \%)$ & 0.617 \\
\hline $\begin{array}{l}\text { Necrotizing } \\
\text { enterocolitis }\end{array}$ & $1(2.04 \%)$ & 0 & 1.000 \\
\hline
\end{tabular}

Table 7 shows all the special interventions like ventilation by continous positive airway pressure, surfactant use and phototherapy required in neonates in both the groups. The interventions were required more in neonates in group B (i.e.24 hour group) however none of them reached the level of clinical significance.

Table 7: Special interventions required in both groups

\begin{tabular}{|l|c|c|c|}
\hline Intervention & $\begin{array}{c}\text { Group A } \\
(\mathrm{n}=49)\end{array}$ & $\begin{array}{c}\text { Group B } \\
(\mathrm{n}=50)\end{array}$ & $\mathrm{p}$ value \\
\hline $\begin{array}{l}\text { Ventilation by } \\
\text { CPAP }\end{array}$ & $7(14.28 \%)$ & $11(22 \%)$ & 0.298 \\
\hline Surfactant use & $2(4.08 \%)$ & $7(14 \%)$ & 0.160 \\
\hline Phototherapy & $37(74.51 \%)$ & $42(84 \%)$ & 0.220 \\
\hline
\end{tabular}

\section{Discussion}

The present study was planned to assess the effect of giving two doses of Betamethasone either 12 hours or 24hours apart on the maternal and neonatal outcomes in women with preterm premature rupture of membranes. Patients were divided after randomization into two groups of 50 women in each and were given Inj. Betamethasone either 12 hours apart (group A) or 24 hours apart (group B).

The women recruited for the two groups had comparable demographic profile. The mean age of women in group A was $26.32 \pm 4.79$ years while that in group B was $26.14 \pm 3.82$ years. The difference was not statistically significant.

In group A $73.51 \%$ had vaginal delivery where as $80 \%$ had vaginal delivery in B. Although vaginal deliveries were more in group A but the difference was not significant. In the study by Khandelwal et 
$\mathrm{al}^{6}$ in which vaginal deliveries were higher $67.8 \%$ in 12 hour group compared to $56.4 \%$ in 24 hour group. But here also the difference was not significant. In our study $6 \%$ women had Postpartum fever in group A while $2 \%$ had Postpartum fever in group B which was not statistically significant, while in the study by Khandelwal et al the incidence of Postpartum fever was lower being $5.9 \%$ in 12 hour group.

Neonatal outcome were noted in the form of primary outcome as Respiratory distress syndrome and secondary outcome as Inraventricular heamorrhage (IVH), Necrotising enterocolitis (NEC) and Neonatal sepsis. In our study the incidence of birth asphyxia was found to be significantly higher in 24 hour group (Group B) than 12 hour group (Group A). The incidence of RDS was also more in group B however it was not statistically significant. Rest of the neonatal outcomes like Neonatal jaundice, Neonatal sepsis, Intraventricular heammorhage were more in group A than B but the difference was not clinically significant. In a study by Kashanian $\mathrm{M}$ et $\mathrm{al}^{7}$ on 201 women found that RDS $(p=0.22), \quad I V H$ $(\mathrm{p}=0.07)$ and chorioamnionitis were more in 24 hour group (gp B). Necrotising enterocolitis was more in 12 hour group ( $g p A ; p=0.038$ ). In the study by Khandelwal et al ${ }^{6}$ done on 228 women, the incidence of RDS was similar in two groups. Women unable to receive complete course with 24 hour interval could be reduced by half by 12 hour interval, however the study found that the 12 hour interval ( $\mathrm{gp} \mathrm{A}$ ) increased the incidence of NEC. In a study by David et al ${ }^{8}$ on 562 women no significant difference was found in the rates of RDS, surfactant use and IVH similar to our study. In the retrospective review done, the outcomes using 12 hour dosing schedule of Betamethasone were similar to those using 24 hour regimen concluding thereby that 12 hour dosing could be considered an alternative way to deliver antenatal corticosteroids.

Surfactant was given to $4 \%$ in group $\mathrm{A}$ and in $14 \%$ in group $B(p=0.160)$. The result did not actually reflect the true situation as surfavtant was needed in more number of patients but could not be given due to non affordability. Khandelwal et $\mathrm{al}^{44}$ had reported rate of NICU admissions (12 hours group $77.5 \%$ vs. 24 hours group $87.2 \%$ with $\mathrm{p}=0.08$ respectively. David et $\mathrm{al}^{8}$ was noted number of neonates who needed ventilation by CPAP (35.4\% vs. $38.4 \%$ ) in group A and B respectively. Surfactant was given to $48.1 \%$ and $40.7 \%$ babies of group A and B respectively.

\section{Conclusion}

The data and the results from the study suggest that the maternal as well as neonatal outcomes were similar in the 12 hours and 24 hours group except birth asphyxia which was seen more in group B i.e. the 24 hours group with statistically significant difference. Rest of the variables were almost similar in the two groups. Thus it seems to suggest that 12 hour dosing interval is equally beneficial as 24 hours and can be offered to the patients. One advantage of 12 hours dosing interval is that it can result in more number of patients completing the course of steroids before delivery compared to the conventional 24 hours dosage schedule. Hence we can conclude that 12 hours dosage schedule can be offered to the women but studies at large scale are required to validate this approach.

\section{Sources of support: None}

\section{References}

1. Singh U, Singh N, Shikha S. A prospective analysis of etiology and outcome of preterm labor. J Obstet and Gynecol.2007; 57: 48-52.

2. Brownfoot FC, Crowther CA, Middleton P. Different corticosteroids and regimens for accelerating fetal lung maturation for women at risk of preterm birth. Cochrane Database Syst. Rev 2008; 4.

3. Canavan TP, Simhan HN, Caritis S. An evidence-based approach to the evaluation and treatment of premature rupture of 
membranes:Part I. Obstet Gynecol

Surv.2004;59(9):669-77.

4. Dale PO, Tanbo T, Bendvold E, Moe N.

Duration of the latency period in preterm premature rupture of the membranes: Maternal and neonatal consequences of expectant management. Eur J Obstet Gynecol Reprod Biol.1989;30(3):257-62.

5. Jobe AH, Nitsos I, Pillow JJ, Polglase GR, Kallapur SG, Newnham JP. Betamethasone dose and formulation for induced lung maturation in fetal sheep. Am J Obstet Gynecol.2009;201:611.

6. Khandelwal M, Chang E, Hansen C, Hunter K,Milcarek. Betamethasone dosing interva:12 or 24 hrs apart?A randomised,non inferiority open trial. Am J Obstet Gynecol.2012;206:201.

7. Kashania M, Eshraghi N, Sheikhansari N, Boardbar A. Comparison between two doses of betamethasone administration with 12 hours vs 24 hours intervals on prevention of respiratory distress syndrome: a randomized trial;Jour Obs\& Gynecol.38(6):1-7.March 2018.

8. Hass DM, McCullough $\mathrm{W}$, Olsen $\mathrm{CH}$, Shiau DT, Richard J, Fry EA et al. Neonatal outcomes with different betamethasone dosing regimen:a comparison. J Reprod.Med.2005 Dec;50(12):915-22. 